\title{
Financing Higher Education in Arab Countries: Challenges, Constraints and Solutions
}

\author{
Huda Alkubaisi ${ }^{1}$, Noorjahan Rasool ${ }^{2}$ \\ ${ }^{1}$ Education Finance, Qatar University, Doha, Qatar \\ ${ }^{2}$ Mumbai, India \\ Correspondence: Huda Alkubaisi, Education Finance, Qatar University, Doha, Qatar.
}

Received: Feb. 10, 2020

doi: 10.11114 jets.v8i8.4708

Accepted: July 5, 2020

Online Published: July 20, 2020

URL: https://doi.org/10.11114/jets.v8i8.4708

\begin{abstract}
This study related to the HE finance system aims primarily to systematically identify, summarize, examine and critically analyze the key challenges and constraints confronting HE finance as investigated in the research on this subject and propose solutions for further improvement. The findings from the defined sample of 24 relevant studies showed that major constraints and challenges facing HE financing certainly affects the flow of adequate finance provided to HEIs, including brain drain, existence of a gap between educational outcomes and labor market, reliance on policy learning and dependency on others, financial crisis, shortage of governmental resources, and poor participation of the private sector and civil society. The constraints and challenges were identified based on insightful theoretical constructs that highly characterized by principles and concepts which may not allow us to practicably develop a clear understanding of how to inspire the development of HE finance that would be a concern of policymakers and speedily acts on policy-making. However, the integration of such theoretical constructs (or others) and the introduction of serious attempts or thoughtful scenarios towards practical applications are mostly ignored. The need to acknowledge the constraints associated with limits on finance is fundamental for declining the hazardously high levels of unemployment for a sustainable economic growth. Finally, quantitative and mixed method research designs, and cross-sectional and panel analysis data are recommended to assess the influence of the HE finance systems and to identify the best opportunities and ways to meet challenges confronted by the countries, given their social and political paradigms.
\end{abstract}

Keywords: higher education, higher education financing; constraints, Arab world

\section{Introduction}

Redefining Higher Education (HE) systems and practices to better respond to the multiple, and at times clashing, requirements and demands of global and internal contexts, technological advancements as well as workforce equalities has always been essential. HE is a resource for the labor market and economic and social developments. Education is generally the drive for developing and sustaining rapid change, and it inspires a culture of innovation and also motivates social development (Hallinger \& Hammad, 2019). Therefore, there is a great emphasis, in economics, on HE and on obtaining the knowledge, skills and competencies necessary to survive and succeed in the neo-liberal economic market (Buckner, 2011; UNESCO, 2013).

Considering HE as a strategic investment (Al-Juma'ai, 2015) and an essential component to respond to the global demands of liberalism (Banya, 2005), the Arab region has witnessed heavy growth in this sector over the last thirty years. The continuously increasing demand for HE has also encouraged private, semi-private and public-private HE institutions (HEI). The number of public and private universities in these countries has grown from merely 13 in the 1950s to more than 700 post-secondary institutions today, enrolling more than 13 million students (UNESCO, 2018). HE has become a dominant priority in the region. Although there are various indicators which show that HE in the Arab context "is on an upward trajectory" (p. 3), HE systems face many challenges and barriers for a number of reasons (Badran, Baydoun \& Hillman, 2019) that stand in the way of policy implementations and improvements that are mostly pertinent to HE finance. Limited HE funds and financial resources in the region and the increasing global cost of $\mathrm{HE}$ have significantly affected the adequacy and productivity of this sector, which calls for further research.

$\mathrm{HE}$ is widely accepted as a national priority in the Arab nations as it fuels a country's development goals by clearly linking outputs and skills and knowledge development to job market demands. According to Badran at al. (2019), the 
changes and impact of growing globalization on HE have speedily travelled to the countries associated with challenges about the provision of programs and instructional structures of HEIs. And yet, the context, nature and structure of educational systems vary widely between these nations (Bowers, Shoho \& Barnett, 2015). Our current review of HE finance offers explanatory insights into the topic and pertains to most, but not all, countries in the region. Apparently, educational research context is still relatively immature in most Arab countries and there is only a little consideration for the level of practice, which is received and employed in isolation from their theoretical base (Sellami et al., 2019). On the contrary, HE finance has received significant attention in the Arabic research and has insightfully contributed to the development of our body of knowledge (see Saa'q (1986), Shaa't (1997), Abdeen (2017) and Al-Theibi (2016) and (Badran, at al., 2019)). Our knowledge about a systematically reviewed literature, as a methodology, in the region, has been rather limited. Thus, the primary purpose of this study, however, is to highlight how the 'HE finance' was defined in the existing body of research in Arab countries. This review aims also to systematically identify, summarize, examine and critically analyze the key constraints and challenges confronting HE finance as investigated in this research, and to identify the key solutions for further improvement. Moreover, the contemporary situation seems to be precarious, specifically in relation to forming HE systems that ensure human development. The significance of this review, therefor, being that it actively contributes to the considerable attempts already made to achieve desired stability in workforce quality produced by HE for a sustainable economic growth.

It is, therefore, our interest to navigate the exciting research on HE finance in the eye of the beholder, rather than attempting to confirm the validity of the research's findings. Thus, we believe that reviewing HE finance in this particular context has significance for adding more insights to the topic so as to better understand it. The following research questions (RQs) guided this review:

(1) What are the major constraints and challenges in the research about HE financing in Arab countries?

(2) What are some possible key solutions to minimize the impact of constraints and challenges identified in the research?

The paper is organized as follows: first, a description and contextual insights grounded in the scenarios of and rational for financing $\mathrm{HE}$ in the region is discussed. A theoretical discussion and RQs are presented in the subsequent section. Then, a summary of the method employed for selecting and reviewing the research is outlined, including search strategy, analysis and evaluation of the reviewed research. Finally, the study's findings and conclusion are presented.

\section{Review of the Literature}

\subsection{Introduction}

This section of the literature review describes the Arab world context, its definition and its culture. It also discusses the HE systems and funding, and the existing methods of spending on education in the region.

\subsection{The Context of the Arab World}

It is important to describe the Arab world in order to understand the context of the current study. The Arab world is situated in an area of 13.13 million $\mathrm{km}^{2}$ and consists of 22 countries, including Algeria, Bahrain, Comoros, Djibouti, Egypt, the United Arab Emirates, Iraq, Jordan, Kuwait, Lebanon, Libya, Mauritania, Morocco, Oman, Palestine, Qatar, Saudi Arabia and Somalia. All of these countries are part of the Arab League, which is a union of Arabic-speaking African and Asian countries whose goal is to strengthen the economic and strategic collaboration of the member states and further their individual and collective interests. The Arab world has an estimated population of around 423 million Arabic-speaking people. Besides their shared language heritage, these people share a similar history, Islamic identity and values, and many socio-cultural structural aspects. However, these states do differ in other ways, such as politics, economy and education (Arar \& Oplatka, 2015; Oplatka \& Arar, 2017).

According to Mallett et al. (2012, p.454):

"international development is a multi-disciplinary field in nature, it may be much harder to assess evidence compared to the fields in which systematic reviews were pioneered. There is a need to adapt the methodology to make systematic reviews work for international development and humanitarian research, and finding ways to achieve this will only happen through experimentation with the process."

Therefore, this study was motivated by a personal desire to provide some useful insights into the views of how the challenges that confront HE finance are perceived in the research from Arab countries. Connected with this is the context of the target nations, which influences education and is likely characterized by common contextual social and some political factors, and shared aspects like language, religion and history (Arar \& Oplatka, 2015; 2017). The social factors are fundamental to most in educational systems, and are developed and maintained at a cultural level (Hallinger 
\& Hammad, 2017, Alkubaisi, 2018). This is to acknowledge that we, throughout the present study, consider that Arab societies, despite some political, economic and contextual differences that exist between them (Arar \& Oplatka, 2015), are likely to have some similarities in terms of educational policies, influences, beliefs, national identities and social goals for the future.

With the growing pace of social and technological changes and the overwhelming impact of globalization, HE marketing has become a key to national economic productivity, development, and competitiveness (Drori, 2000; Hemsley-Brown \& Oplatka, 2006: Badran et al., 2019). Given the consequences of globalization and its dynamics, HE systems in the Arab region have become more challenging to meet both global and national demands and expectations (Badran, at al., 2019).

\subsection{Understanding HE Finance in Arab Countries}

The HE primary source of finance is mostly the public money from governments (World Bank, 2000; UNESCO, 2018) reached up to about $90 \%$ of all funding sources, whereby the government deducts substantial amounts of revenues from national projects in order to allocate funding for HE. Whereas the $10 \%$ is mostly covered through student fees, as well as internal assistance (private sector contributions) and, in some countries, external assistance (foreign countries, organizations, and international bodies) (Sanyal, 19980. Taxes, student loans, scholarships, individuals' self-payments, tuitions fees, and financial contributions and donations (Muhammad, 2006) are the evident sources for HE. HE finance is viewed as "the most ubiquitous policy tool by a state to influence institutional behavior" (Banya, 2005, p.160) in the region. Spending on HE represents only 5\% of international expenditure on education (Al-Agtash \& Khadra, 2019). For the World Bank (2019a), the sufficiency of this amount to ensure the success of HEIs is the subject of much debate.

Overall, the public university is the main form of HEIs in the Arab context, representing $65 \%$ of the total number of institutions. Private institutions are also variedly and increasingly contributing to the educational system, with 5\% to $40 \%$ student enrollment (Al-Agtash \& Khadra, 2019; UNESCO, 2018). Nevertheless, the conflict between financing public and private HEIs has been optimally balanced, but lack of communication is evident (UNESCO, 2018). However, the "two major blocks in financing HE are the public funds in the public sector and the tuition fees in the private sector" (UNESCO, 2018, p. 14). Al-Agtash and Khadra (2019), in reference to some other sources, ${ }^{1}$ indicate that such government funds are still insignificant. It is noticeable that HE in developing countries, including the region, is "under great strain [and is] chronically under-funded, but face[s] escalating demand" (World Bank, 2000, p. 12).

The contribution from the private sector includes private and commercial organizations, which are not related to the public sector by any means and/or are not involved in the administration of government agencies such as ministries. Such private contributions are represented in the provision of periodic (often annual) payments to support the educational system. Payments are offered based on agreements drawn with the HE bodies of authority. The trend today is to share the costs between governmental entities and university and community entities, with some loading of part of the costs of HE onto the student. This represents the model of funding sources for the most prestigious Arab universities (Shaheen, 2016).

In addition to public and private funds, there are other sources of funding for HE in the region, including endowments, donations, grants, fundraising activities, and the financial returns from hiring facilities, research, consultations, and other educational services, such as open and parallel education programs, invention and innovation, and professional and commercial activities. Whatever the type of financial resources may be considered appropriate for a HEI, it should be capable of meeting its needs and fully covering its expenses related to achieving its agenda, educational and research landscapes and priorities, aimed at improving the efficiency of teaching and learning and the quality of the services provided (Ghanem, 2000), the. Likewise, Badran and Badran (2018) argue that the budgets must be adequate, competitive and capable of preserving a workable financial structure that can cover operating expenditures, infrastructures, equipment and facilities, and salaries. More explicitly, adequate financing is what HEIs in the region count on in order to achieve their desired learning objectives and their optimal preparation of human potential according to the diverse competencies required for appropriate human capacity preparation and development (Rahaf \& Al-Obeidi, 1998). It is indispensable for the development and the achievement of quality education in HE, which ultimately supports and contributes to the economic development of a country. While quality may be a multi-dimensional and somewhat subjective notion, it is generally interpreted as being "fit-for-purpose" (UNESCO, 2018, p. 18). In the current context, it denotes the ability and competence of HEIs to achieve their stated objectives, envisage agendas and institutional missions, and respond as appropriate to the larger context of labor market requirements (UNESCO, 2018).

Moreover, there are growing pressures to improve the quality and performance of HE programs and to incorporate the use of technology among other demands. Therefore, financing plays an integral role in securing the ability of HE systems to build the capacity of future generations of human resources for development. Ensuring appropriate financing

\footnotetext{
${ }^{1}$ League of Arab States (www.lasportal.org) and Association of Arab Universities (www.aaru.edu.jo)
} 
and necessary financial resources would bring more opportunities for creativity, innovation and evolution to the particular institutes. This can be accomplished by, among others, ensuring free access to HE and benefiting from provided services in existing institutes. Similarly, the focus on financing allows for a better understanding of how financial needs can be better shared and allocated among state, public, private, and other possible parties in society based on adequate statistical data. Researchers agree that the "clientele bearing the blunt of higher education seems to be the way higher education is obtained; this is in line with the concept of globalisation, i.e., the market mechanism" (Banya, 2005, p. 161).

\subsection{Spending on Education}

Abu Al-Wafa and Abualadim (2000) have defined education finance as the sum of resources allocated, including funds, to educational institutions within a nation's targeted framework for education with the goal of using them efficiently. These funds furnish vital capital costs for HE goals and projects that need to be conceptualized according to concrete and thoughtful implementation plans, well-calculated financial strategies, appropriate action plans and regulatory frameworks, and well-defined timelines. The significance of this definition is likely relevant to its emphasis on the economic rather than administrative dimension of finance. AlAzmi (2005) argues that spending on education should include the funds provided for building schools and their attendant physical, technical and non-technical needs, including classrooms, laboratories, playgrounds, learning resource centers, workshops, libraries and personnel salaries.

Some researchers have highlighted methods now widely considered in Arab countries for financing HE. This includes four broad themes (Badran \& Badran, 2018):

(1) Oil-producing countries, i.e., the Gulf States, provide free public HE with monthly stipends to their citizens pursuing post-secondary studies.

(2) Egypt, Syria, Iraq, Algeria and Yemen, where education is not a high priority, offer state supported free HE. However, there is a concern that this subsidized support may be drastically reduced by governments, even less than the tuition payments.

(3) Lebanon, Jordan and the Palestinian territories, despite their few natural resources and deficient financial support, do provide free general education. They also receive some private funds from other sources, e.g., tuition payments. However, free access to education does not guarantee equal opportunities for everyone.

(4) Private universities are privately funded but centrally licensed and controlled by Ministries of HE in these countries. Private universities include non-profit universities whose revenues are re-invested to improve the infrastructure and to enhance the quality of education and research, and also for-profit universities whose generated income is distributed among stakeholders. It is important to note that the private HE system is rather robust and powerful in the Gulf region and Lebanon and is preferred by wealthy families and that has reduced government spending on education. Faim and Sami (2009; 2011, as cited in Alshamy, 2012, p. 4) assert, "public spending on HE across different population quintiles favours the rich." However, it remains a rarity in many countries that are more dependent on public education (UNESCO, 2018).

Similarly, there are three other important structures of financing HE in Arab countries: external financing, cost-sharing and state-private combined provision of HE. In external financing, foreign countries or so-called 'donor countries' offer funds for regional initiatives and educational projects for the benefit of poorer, middle-income, or developing Arab countries. The receiving countries often acknowledge these funds and their sources by mentioning the donors on the front pages of textbooks, curricula and other instructional materials. Noticeably, in many developing countries, HEIs are financed by international agents such as the World Bank (Fehnel, 2004). Cost-sharing (or student-aid) between the students/families and governments is another possible structure for funding HE (OECD \& World Bank, 2010a). Government provisions can take the form of either refundable loans or non-refundable governmental grants, fellowships or scholarships (Goastellec, 2005; UNESCO, 2018). A third possible structure is state-private combined provisions of HE through offering local or partnership programs with international institutions (UNESCO, 2018).

Furthermore, Al-Hilali (2003) distinguished between two different rationalities combining for HE spending in the region:

(1) Spending would help reduce poverty rates. The visible imbalance of employment opportunities and job market outcomes have worsened poverty levels (Hanieh, 2016). HE leads to higher economic productivity through quality education and thus also leads to the empowerment of workers. In turn, this increases the income of the poor, since with HE their educational asset becomes the means to reduce the income gap between themselves and the wealthy. Furthermore, public spending on basic education mostly benefits the poorest of society because the rich can always turn to private education if they need to. Thus, governments must work to equalize opportunities between citizens, especially among those whose circumstances may not allow them to afford HE. Education is a catalyst for the 
formation of human capital, socioeconomic mobilization, higher productivity and social capital (MacLeans, 2005).

(2) The greater demand for human capital, either for economic growth or personal or social development, has increasingly and quickly accelerated the demand for HE, which has become more customized to meet the market's needs (Sanyal, 1998). It could be argued therefore that spending on education has increased the nature of the public capital market from which HE can be funded, rather than being solely a tax-borne activity.

The sharp rise in student numbers has increased the funding required and the demand for education provisions (Alnoori, 1987). Okal (2011) states that spending on education in the region increased from US\$307 million in 1970 to US\$7 billion and US\$10 billion in 2000 and 2008, respectively. Despite this rise, such spending - and relatedly also the per capita expenditures on education - the gap between many of these countries and developed countries is glaringly apparent (Alnoori, 1987). Having said that, the variation in the spending per student between these countries themselves is evident. For example, In the World Bank (2019a) report indicates that the amount spent on education in the Gulf countries (e.g., Qatar, Kuwait, and UAE) is noticeably higher than other wealthy countries (World Bank, 2019a). This report also indicates that while $11.3 \%$ represents the average spending of OECD countries on education, $20.6 \%$ of the Tunisian public budget is allocated for education. However, despite being relatively high, this allocation has decreased from $20.6 \%$ in 2000 to $13 \%$ in 2016 (World Bank, 2019a). While there may be several ways to read this data, generally, as Al-Agtash and Khadra (2019, p. 70) suggest, it may be thought that "there is a growing move towards developing better education systems with more technologies being integrated to keep in pace with recent advancements and trends." Nonetheless, the current situation of Arab HE is not encouraging. UNESCO (2018) reveals that HE finance provisions and resources are still insufficient in many Arab countries.

Findings of a comparative study related to the cost of education indicate that the cost of a student in HE in developing countries is equal to 12 times the cost of a secondary school student and 88 times that of a primary school student (Psacharopouls \& Sanyal, 1981). According to Schultz (1961), education is a materially costly project that requires the continuation of funding sources as the latter determines decisions related to human development. Likewise, this region places greater expectations on HE as a driving force for economic development (Karakhanyan, 2019), but researchers agree that $\mathrm{HE}$ is not yet progressing and is fraught with obstacles that mainly concern limited finance and insufficient resources (Banya, 2005; Sabry, 2009; Johar \& Al-Basil, 2015, Al-Agtash \& Khadra, 2019). We also agree that neither funds collected through tuition fees, donations, nor even government are enough to finance HE in the region. Moreover, we believe that the attention, which has been paid for HE funding as a part of the developing paradigm, makes it necessary to attempt to understand this concept in this particular context. Therefore, this review may offer the focus needed in attempting to bridge this gap and provide significant insights to the topic being investigated as placed in the current political, social and economic context. Yet, education remains a fundamental right of individuals in modern societies.

\section{Methodology}

In this study, we have developed a framework for determining the research literature, i.e. investigating the selected studies, and assessing evidences, influenced by Boell and Cecez-Kecmanovic (2015) as shown in Figure (1) and described below.

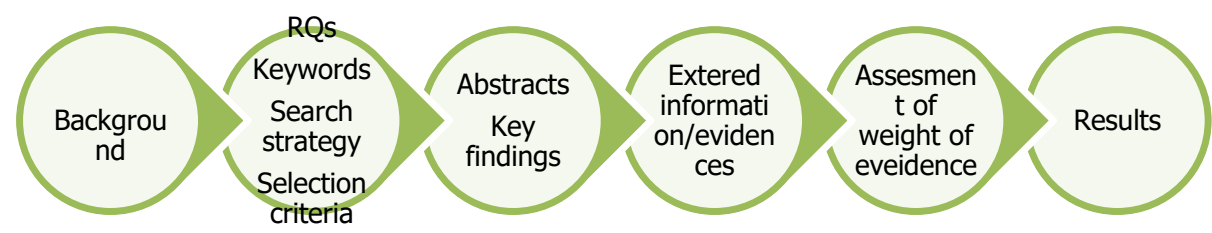

According to Dixon-Woods (2011), systematic review is "a scientific process governed by a set of explicit and demanding rules oriented towards demonstrating comprehensiveness, immunity from bias, and transparency and accountability of technique and execution" (p. 332). It is, therefore, perceived as objective, systematic, replicable and duplicable, and follows empirical research reporting approach compared to traditional literature (Weed, 2005). The purpose of this study was to systematically identify, summarize, examine and critically analyze the current body of research that qualitatively investigated HE finance in a given context. Therefore, we considered weight of evidence (Gough, 2007; Davies et al., 2013) as a manner for overall classification of the selected research. Several measures and steps of search were considered in this study as a methodology to manage and synthesize research in a systematic, evidence-drive, and unbiased approach believing that would allow replicability (Oakley, 2003; Thorpe et al., 2006, 
Gough, 2007; Thomas \& Harden, 2008; Booth, Papaioannou \& Sutton, 2012; Mallett et al., 2012).

\subsection{Searching to Identify Search Terms}

The first step represents deploying electronic search engines or databases acknowledged in education that are capable of retrieving information and making decisions about identification related published literature to the topic, including e-books and journal articles available in Google Scholar, and some scholarly databases and catalogues with search facilities, open repositories and data archives that are available as an online accessible tool through a present researcher's university library electronic system. ${ }^{2}$ The following electronic databases were used: Al Manhal database, Dar Al Mandumah Edusearch, Chronicle of Higher Education, and Eric. One of the researcher searched three databases (Al Manhal database, Dar Al Mandumah Edusearch and Eric), whereas the second researcher searched Google Scholar and Education.

This round was driven by the RQs and objectives and searching was limited to the abstracts of each reviewed research studies. Furthermore, grounding on a set of pre-defined keywords related to the RQs and context (Table 1) and analysis of these abstracts we established our strategy to identify a reliable evidence-based intervention relevance literature whereas a focus on relevance to the RQs was maintained. This strategy permits the incorporation of "data across studies, where they have similar outcome measures and the summary of findings where methods used are diverse" (Michie \& Williams, 2003, p. 3). The titles of all screened abstracts were taken into consideration and recorded by the researchers. This round of the review explicitly examined research on HE finance in a given context. As the aim was to offer explanatory insights into the topic in HE, we excluded studies primarily centered to the education systems in general.

Table 1. Keywords used in research search engine (as appeared in abstracts)

\begin{tabular}{l|l|l}
\hline $\begin{array}{l}\text { Title and abstract matching } \\
\text { criterion }\end{array}$ & $\begin{array}{l}\text { Number of studies in the five } \\
\text { searched engines }\end{array}$ & Percentage \\
\hline $\begin{array}{l}\text { Studies resulted by key words } \\
\text { included in the abstracts and titles }\end{array}$ & 61 out of 85 & $71.68 \%$ \\
in search engine in the $1^{\text {st }}$ screening & & $100 \%$ \\
\hline $\begin{array}{l}\text { Studies resulted by key words } \\
\text { included in the abstracts and titles }\end{array}$ & & \\
in search engine in the final 24 & \\
screening
\end{tabular}

\subsection{Identification of Sources to Be Searched}

Following this, the outcome of the research obtained from the databases listed above was re-examined in a more systematic manner in a subsequent round of a literature review for a largely homogeneity between the abstracts which had been identified earlier. The purpose was maintaining a "comparative power" (p. 3) of our screening (Hallinger \& Hammad, 2019) to be able to manage and analyze the review in order to evaluate eligibility against selection criteria to ensure unbiasedness (Thomas \& Harden, 2008; Davies et al., 2013) and render the outcome of this screening transparent (ibid). In this subsequent activity, we re-searched the re-identified the abstracts to ensure that only possible relevant ones to the RQs had been included. According to Gough and Elbourne (2002), RQ(s) is a key factor and is fundamentally significant for decisions, for example, inclusion and exclusion criteria, that are made about the review.

\subsection{Selection Criteria}

Initially, the search strategy was driven by some selection (i.e. inclusion and exclusion) criteria to identify the abstracts (and then the retrieved full text research studies) to be reviewed: (1) the search strategy was limited to a search of electronic search engines or databases that were listed above only; (2) research published from 2004 to 2019 was considered; (3) the research relates to the current context, i.e., the Arab world that discusses HE finance as the main topical theme that searched sublimated by four keywords 'Higher education' finance', 'constraints', 'challenges' and 'solutions'; (4) limited to abstracts only; and (5) visibly relevant to the RQs. Examined abstracts with any of the above four criteria missing were excluded (see Table 2). To enhance the search keywords, other keywords' synonyms were identified (e.g. HE, HE universities/institutes/institutions funding/funds, Arab countries/states/zone/context, constraints/obstacles/problems, and solutions/suggestions/recommendations) (see Table 2). The potential relevance of the selected sources rests on transparency, accessibility, insurance of meeting our selection criteria and the ability to generate reliable findings.

\footnotetext{
${ }^{2}$ http://library.qu.edu.qa/en/\#.Xst5RmgzY2w.
} 
Table 2. Keywords' synonyms used in search

\begin{tabular}{|c|c|c|}
\hline \multirow[t]{2}{*}{ Keywords' synonyms } & \multicolumn{2}{|c|}{ Search for both keywords } \\
\hline & Keyword 1 & Keyword 2 \\
\hline \multirow{5}{*}{$\begin{array}{lrr}\text { Search for } & \text { either } \\
\text { keyword } & 1 & \text { or } \\
\text { keyword } 2 & & \end{array}$} & $\mathrm{HE}$ & \multirow{4}{*}{$\begin{array}{l}\text { Obstacles } \\
\text { Constraints } \\
\text { Problem } \\
\text { Challenges }\end{array}$} \\
\hline & Universities & \\
\hline & HE institutes/institutions & \\
\hline & $\begin{array}{l}\text { Funding } \\
\text { Funds }\end{array}$ & \\
\hline & $\begin{array}{l}\text { Arab countries } \\
\text { Arab states } \\
\text { Arab zone } \\
\text { Arab World }\end{array}$ & $\begin{array}{l}\text { Solutions } \\
\text { Suggestions }\end{array}$ \\
\hline
\end{tabular}

\subsection{Sources Management and Sample}

After finding eligible sources that meet the five selection criteria, 85 abstracts were identified and carefully reviewed. Following this, each abstract underwent a second screening against the inclusion criteria, resulting in limiting them to 61 studies after removing the duplicates. Furthermore, aiming to generate an appropriate and representative sample, and get more relevant studies to answer our RQs, the 61 studies again underwent a third screening that led to a final sample of 24 relevant studies. At this screening, all reviewed abstracts were carefully re-screened on the relevance of their titles and only those matching to their titles (by including pre-established search keywords) were selected. Mallett et al. (2012) indicate that many systematic reviews increasingly rely on the deployment of clearer abstracts and titles.

24 full text studies were selected and retrieved and were printed out in hard copy for this review. These studies were varying and drawn from range types of research. All screenings and decisions, and well ahead reviewed were made by both of us to explore the topic. Table 3 presents the outcomes identified through all screenings and the number of studies included based on the database through which they were accessed.

Table 3. Screenings rounds and type literature based on the database identified.

\begin{tabular}{|c|c|c|c|c|c|}
\hline \multirow{2}{*}{ Screening } & \multirow[b]{2}{*}{ Database } & \multicolumn{3}{|c|}{ Type of literature/manuscript } & \multirow[t]{2}{*}{ Count } \\
\hline & & Book/chapter(s) & $\begin{array}{l}\text { Journal } \\
\text { article/review }\end{array}$ & Report/Monograph/document & \\
\hline \multirow[t]{5}{*}{ I } & Google Scholar & 5 & 10 & 5 & \multirow{5}{*}{85} \\
\hline & Al Manhal database & 5 & 10 & 3 & \\
\hline & $\begin{array}{lrl}\text { Dar } & \text { Al } & \text { Mandumah } \\
\text { Edusearch } & \end{array}$ & 4 & 13 & 3 & \\
\hline & $\begin{array}{l}\text { Chronicle of Higher } \\
\text { Education }\end{array}$ & 3 & 7 & 5 & \\
\hline & Eric & 3 & 6 & 6 & \\
\hline \multirow[t]{5}{*}{2} & Google Scholar & 5 & 6 & 5 & \multirow[t]{5}{*}{61} \\
\hline & Al Manhal database & 4 & 8 & 2 & \\
\hline & 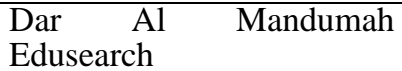 & 2 & 7 & 3 & \\
\hline & $\begin{array}{l}\text { Chronicle of Higher } \\
\text { Education }\end{array}$ & 1 & 3 & 3 & \\
\hline & Eric & 2 & 4 & 2 & \\
\hline \multirow[t]{5}{*}{3} & Google Scholar & 3 & 3 & 2 & \multirow[t]{5}{*}{24} \\
\hline & Al Manhal database & 2 & 3 & 1 & \\
\hline & $\begin{array}{l}\text { Dar Al } \quad \text { Mandumah } \\
\text { Edusearch }\end{array}$ & 1 & 4 & 1 & \\
\hline & $\begin{array}{l}\text { Chronicle of Higher } \\
\text { Education }\end{array}$ & 0 & 2 & 1 & \\
\hline & Eric & 1 & 0 & 0 & \\
\hline
\end{tabular}

\subsection{Summarizing and Synthesizing the Findings}

RQs building process locates "the synthesis within its context - including its theoretical context" (Gough \& Elbourne, 2002 , p. 232). In this review, we used a narrative synthesis approach relying on descriptive data synthesis that "uses words and text to summarize the findings of multiple studies [...] to explore heterogeneity descriptively rather than statistically" (Booth et al., 2012, p. 183). Guiding by the RQs, we extracted information from the selected studies' abstracts and key findings under two main domains or sections: constraints/challenges and 
solutions/suggestions/recommendations, in order to synthesize and analyze our review. To synthesize this information, we attempted to make them visible by utilizing the narrative approach. As a result, we found that a large number of the studies were relevant to RQ1 as shown in Table (4) below.

Table 4. Numbers and percentages of information in the studies relevant to the RQs

\begin{tabular}{l|l|l}
\hline No. of RQ being addressed & No. of information addressing the QR & $\begin{array}{l}\text { Percentage of information } \\
\text { addressing QR }\end{array}$ \\
\hline $\mathbf{R Q 1}$ & 21 & 87.5 \\
$\begin{array}{l}\text { Includes the studies that address } \\
\text { both RQs }\end{array}$ & 19 & 79.16 \\
\hline $\begin{array}{l}\text { RQ2 } \\
\begin{array}{l}\text { Includes the studies that address } \\
\text { both RQs }\end{array}\end{array}$ & 18 & 75 \\
\hline RQs 1 +2 & 18 & \\
\hline
\end{tabular}

Furthermore, the recommendations that we proposed in this study were based on the information synthesized in the phase above.

\subsection{Data Analysis}

Based on the selected studies, information exerted from the abstracts and key findings relates to the following: 1) What are the major constraints and challenges in the research about HE financing in Arab countries? and 2) What are some possible key solutions to minimize the impact of constraints and challenges identified in the research? This was organized based on Garrard's Matrix Method (2007) for reviewing literature, which is "a structure and a process for systematically reviewing literature" (Cho \& Marshall Egan, 2009, p. 436). As stated earlier, the weight of evidence was undertaken as an approach to assess and classify findings from the selected studies, which led us to define the quality guide using a three-point scale to show the quality of selected studies (see Table 5). This is bearing in mind that the selected studies' reliability was evaluated by valuing each study's methodological quality and relevance (Davies et al., 2013).

Table 5. Quality Guide

\begin{tabular}{|c|c|c|}
\hline Quality guide & Methodology & Title \\
\hline High value & $\begin{array}{l}\text { Adequate aims and rigorous research design } \\
\text { appropriately and clearly indicated. } \\
\text { RQs clearly stated and addressed in the Findings. } \\
\text { Context adequately identified. } \\
\text { Trustworthiness measures properly established } \\
\text { Sound findings that address RQs reached and } \\
\text { conclusions drawn from the findings. } \\
\text { Conclusions are trustworthy and sufficiently } \\
\text { explained }\end{array}$ & $\begin{array}{l}\text { (A lot) Very closely and tightly aligned to } \\
\text { QRs } \\
>5 \text { key words/synonyms included }\end{array}$ \\
\hline Average value & $\begin{array}{l}\text { Aims and description of research design clearly } \\
\text { stated. } \\
\text { RQs stated and fitted the findings. } \\
\text { Satisfactory context description provided. } \\
\text { Valid and reliable findings presented. }\end{array}$ & $\begin{array}{l}\text { Broadly aligned to one/both QRs. } \\
\text { 5-3 key words/synonyms included }\end{array}$ \\
\hline Low value & $\begin{array}{l}\text { Vague aims and/or inappropriate research design } \\
\text { noticed. } \\
\text { RQs unclearly stated and does not fit the findings. } \\
\text { Little or unsatisfactory descriptions of context. } \\
\text { Trustworthiness inadequately adopted. } \\
\text { Weak findings. } \\
\text { Findings and conclusions inseparable. }\end{array}$ & $\begin{array}{l}\text { Slightly aligned to one/both QRs. } \\
<3 \text { key words/synonyms included }\end{array}$ \\
\hline
\end{tabular}

In the next section, the findings are structured around, and presented under, the current RQs. 


\section{Findings}

Generally, this systematic review reviewed abstracts and key findings of a sample of 24 varying qualitative studies to explore our topic within the particular context and themes. Thus, the review identified two main themes in the research about HE funding in Arab countries based on the RQs as discussed below.

\section{What are the major constraints and challenges in the research about HE financing in Arab countries?}

The analysis of the 24 studies relevant to this question illustrates that five key variables emerged which appear to be major constraints of HE funding in the region:

\section{i. Brain drain}

Brain drain is a phenomenon defined as "the migration of the highly-skilled and educated people [...] especially from developing countries to developed countries [... and] has a college degree" (Ozden, 2006, pp. 2-3). In other words, outstanding and distinguished graduates from Arab universities usually receive scholarships to pursue their studies in Western universities and/or institutions. When potential graduates join such a university/institution, they most likely excel and are expected to receive further financial aid or additional scholarships (including being offered research grants, development grants and other encouraging learning opportunities). In this economically and socially attractive situation, and the ascribed enjoyment of this privileged status, this group of students is understandably inclined to settle in those host countries. The location where graduates choose to have their education is the most significant factor of the brain drain paradigm (Ozden, 2006). Contextual factors such as access to best research hubs, optimal job opportunities, better social status, continued quality education, high income, and, in many instances, legal and citizenship considerations are strong determinants of choice of location. The absence of similar such opportunities in their home country likely drives these graduates to decide to live elsewhere. UNDP and RBAS (2016) claims that this is commonly a response to the dearth of educational and career opportunities. Thus, in this way Arab countries lose hundreds, even thousands, of their prime potential researchers, professionals and thinkers every year. Put otherwise, Western countries reap what Arab countries sow. The estimated number of Arab migrants in 2010-2014 reached 22,070,300, which represents approximately $6.1 \%$ of the total population (UNDP \& RBAS , 2016).

Although researchers have debated whether people who have never changed their citizenship are not a "loss" for their home country (Ozden, 2006), the result of this movement is certainly damaging to the region. This is because the Arab region gradually loses potential graduates who are highly educated and who can lead and encourage creativity, innovation, inventions and knowledge creation in the region (Ozden, 2006; Beltagi, 2012). They, therefore, represent highly valuable human capital (Ozden, 2006). This is a prevailing paradigm in the non-oil-producing/exporting Arab countries. Statistics reveal that the main Arab countries exporting a high percentage of emigrants to other Arabs in non-Arab countries are Lebanon, Syria, Iraq, Jordan, Egypt, Tunisia, Morocco and Algeria (Sanyal, 1998).

\section{ii. Gap between educational outcomes and labor market}

World Bank Data (2019b) show that the unemployment rate in the Arab world was $9.6 \%$ in 2016. The unemployment rate in Tunisia was $15.5 \%$, followed by $15.3 \%, 12.4 \%, 10.8 \%$, and 9.3\% in Jordan, Egypt, Iraq and Morocco, respectively. The unemployment rate reached $9.81 \%$ in 2018 (World Bank, 2019c) but is predicted to remain at 7.3\% in 2020 (ILO, 2019), with the possibility that the rate of non-GCC countries is twice as high as that of the Gulf Cooperation Council (GCC) countries. The data is argued to "hide large regional disparities" (Hanieh, 2016, p. 1). It should be noted that expatriates make up more than $41 \%$ of total employment and about $50 \%$ employment in GCC states (ILO, 2019). There is evidence that Arab countries are globally at a lower level of job market participation rates, with less than $50 \%$ of the whole population involved in the market (IMF, 2011).

In other words, thousands of graduates in the Arab world have successfully completed their studies but have found themselves without a job for one reason or another. Some work at jobs that are far below their qualifications or university specialization. For example, 30\% of Egyptian, Tunisian and Jordanian university graduates were unemployed in 2012 alone, including 60\% unemployed women in Jordan and 40\% in Egypt (Hanieh, 2016). This would give one the general impression that university education serves no purpose. Hanieh (2016) indicates that HE graduates in the region have not performed well in job markets, and any attempt to reduce government spending and employment may lead to a significant missing-out on appropriate job opportunities for many young graduates. Thus, young people prefer either to move toward vocational education and work at an early age or to pursue immigration plans. Finally, studies could not find a specific factor contributing to the dominant unfairness of development patterns throughout the region (Hanieh, 2016).

\section{iii. Policy learning and dependency on others}

In the absence of knowledge and sciences production, Arab universities remain largely dependent on importing knowledge and skills from other intellectual communities, which have their own standards, values and culture. This 
perspective is known as 'policy learning', 'policy transfer', or 'policy borrowing'. Portnoi (2005) points to globalization as a significant consideration for policy learning in developing national policies. To illustrate, many governmental organizations and educational institutions have benefitted and have become more competitive through policy learning. Globalization has made the world a global village, making it easy to adopt the practices that have proven successful in other parts of the world. Through globalization, it is now possible for policymakers to have convenient access to knowledge about global policies and vital educational reforms through the internet, think tanks, cross-border experts, as well as international institutions and NGOs, such as the World Bank, the International Monetary Fund (IMF), the United Nations (UN) among others (Kudrle, 2014). Moreover, the evident role of international agents in financing education in many Arab states has increased accessibility to international educational policies (Merhan, 2018).

It must be noted that educational reforms across the world aim to create educational systems that are 'world class' through effective policy learning (mostly Western-based) that enable the transfer of best practices, and Arab countries are no exception. However, the challenge is that what may be considered a best practice or policy in a particular context may not necessarily be as effective when imported to a different cultural context (Blanchard, 2017). Cultural differences constitute a major challenge that cannot be overlooked. While a nation may seek to import education reforms from another country that is doing well in a particular domain, the differences in culture may impede such efforts. Cultural and language differences may at times create rigid barriers for effective interaction and transfusion of conceptual ideas and practical methodologies (Smith, 2016).

Direct transfer of education practices and policies from one culture to another is often made difficult by country biases and context particularities (OECD \& World Bank, 2010b). Flaws in policy implementation and design occur due to imperfect policy learning practices that overlook the importance of countering country biases and context specificity. Such efforts also sometimes bring about an element of inadequate imitation strategies and benchmarking practices. Alkubaisi $(2018$, p. 51) states, "it is evident that policy borrowing has failed to take into account the impact of differences between education system in the emerging economies and liberal Western countries." Such dependency on others and the culture of consumption and imitation are factors that lead to the melting of national and cultural identity and the withering of traditions in the flood of unforgiving globalization. Therefore, reforming the reality of HE and scientific research as well as knowledge production in the Arab world needs radical organizational and structural changes. These include changing the mindset, developing more efficient administration, increasing budgets at a high rate, and engaging private sectors in funding (Al-Sahlawi, 2000). Developed organizational learning capabilities also help to incorporate the use of learning opportunities that are both long-term and life-long, such as the use of workshops, relevant courses, sabbaticals as well as other forms of training. When the importing of culture develops its organizational learning capabilities, it benefits from a general evolution towards a culture that encourages openness and acceptable calculated risk-taking, which makes the whole process much more effective and efficient. Moreover, many policymakers are involved in distributed and strategic interaction with international organizations that offer consultancy in policy learning, such as the World Bank, the OECD, the EU, and other international bodies and conferences (Seabrooke, 2012). The context of the Arab world is no exception.

\section{iv. Financial crisis}

The huge extension in the number of seekers of $\mathrm{HE}$ and the inability of governments to finance such rapid extension is in fact not limited to the Arab context, rather it is an international trend (Sanyal \& Martin, 2006a; 2006b). Budgets have normally been governed by the countries' economic status which has not faring well in recent times (Sanyal, 1998) for several reasons. While resource allocations for HE in the region were sufficient and met expectations in the last century, $\mathrm{HE}$ is greatly growing, and budgets are failing to catch up with that growth. Therefore, the imbalance between such growth and allocated funds and resources is evident in the region. Furthermore, according to some international estimates, the amount of money allocated to Arab universities is still below the allocations made to many of the world's most renowned universities. For example, while the annual budget of Harvard University was to $\$ 4.2, \$ 4.5$ and $\$ 5.5$ billion dollars in 2012-13, 2014-15 and 2018-19, respectively (Harvard University, 2015; 2017; 2018); the annual budget of a private HEI like American University of Beirut, ranked as the $2^{\text {nd }}$ in QS Arab region university rankings, is \$457 million only for 2018-19 (Office of Institutional Research and Assessment, 2019). And yet, the number of Harvard's and UAB's students was 23.336 and 1708 respectively in 2018-19 (Harvard University, 2018; Office of Institutional Research and Assessment, 2019). This shows that the numbers and the budgets of the Arab world indeed appear meagre in comparison.

\section{v. Shortage of government financial resources}

Tilak $(1997 ; 2005$; 2006) has also argued that the shrinking in public spending on HE is a global crisis that is a current trend today. Most countries have been driven - either by economic reform policies or by an ideology of reduced state intervention - to make serious cuts in public budgets for HE. The percentage of HE funding in the region is not only low 
when compared to the most conservative funding for $\mathrm{HE}$ in other countries, the budgetary portion for education is also much less than that of industrialized and newly industrialized countries. Such a percentage does not seem to be growing at a rate commensurate with that of the growing population and might actually decrease decisively in the future. Funding from private sources remains scant and does not adequately contribute to solving the shortage of HE finance in the region. In addition, other funding sources from education systems within the universities are minimal.

For many nations, including Arab countries, the establishment and provision of HE financing is significantly influential matter of question and somewhat controversial in different ways. The reality is that state funding is currently the traditional source of funding for HE, which is seen as a long-term social investment for sustained economic development. However, HE funding cannot be a responsibility exclusive to the state alone. It requires the contributions and provisions of resources of multiple players in the society.

HEIs anywhere in the world require high financial resources to efficiently and competently achieve their goals. These financial requirements are increasing year by year because of the mounting need to develop programs, plans and research. Many countries face difficulties in providing these necessary financial resources due to the large monetary investment required for HE. This problem manifests itself clearly in developing countries in their heavy reliance on governmental financial resources in order to meet the deficit (Beltagi, 2015).

\section{vi. Poor participation of private sector and civil society}

In Arab countries, the contribution of the private sector in funding HE is still weak, except for the participation of businessmen in funding some HEIs. Thus, HE funding remains largely dependent on the primary source for funding. This is unlike developed countries, where private funding plays an effective role in financing the activity of post-secondary institutions. Among the factors that contribute to this is the high standard of living that enables many people to pay for their children's schooling. Furthermore, industrial, financial, and other institutions play ever-increasing and major roles in funding $\mathrm{HE}$ in their ability to reinvest a portion of their profits and because of the incentives and deductions they receive for their participation in social services. Most Arab countries, on the other hand, lack any such tax incentives or motives. Measures must be taken to make the private sector become more involved in this important societal responsibility. For example, more collective parental participation in decision-making may be a good measure of this sort. Increasing cost-sharing and financial contributions by parents and communities in schooling finance is another measure, yet we believe that would be disproportionate for low-income parents, so we encourage diversification of schoolings that is likely to lead to provide greater choice, autonomy and thereafter competition for all parents. There is a need for political and private support for HE and a need to replace the traditional relationship between the HE system and the government with a cooperative relationship where the civil and private community takes more ownership and more proactively supports the government's efforts to sustain and enhance HE (Al-Rubay'an, 2015).

\section{What are some possible key solutions to minimize the impact of constraints and challenges identified in the research?}

This question of the review sought to discover possible solutions. Our review reveals key insights into optimal solutions for solving the major (or some of these) problems related to HE financing in the region. We have identified them below.

Establish a HE fund in each country. This fund would be used to make capital contributions to public and private institutions and to their students and personnel, and to support HEIs, improve their facilities, renew their services and programs, and increase their effectiveness and efficiency.

Establish a national private fund. This would emphasize and encourage the role of the private sector, which is an essential source of HE funding in all countries of the world.

Implement alternative productive university systems of education. Expand upon these programs so they have a bigger role in funding $\mathrm{HE}$ and processing the challenges that it faces. In particular, work toward finding parallel education arrangements, as discussed above, would enable universities to find new funding sources. As mentioned, these include distance education, evening education, and open education. Furthermore, more revenue-generating activities and services that utilize the expertise of university professors and researchers should be sought, such as in the domains of consulting, health and agriculture. In addition, training and awareness programs that serve to satisfy the needs of the community can also be offered. Other ideas include adopting a decentralized system due to its important economic and political benefits. Furthermore, encouraging services inside universities, such as photography, offset, printing, and leasing some facilities could help to generate additional revenue as long as this does not interfere with the educational process.

Engage businessmen in university councils. This would achieve mutual interaction in the fields of counseling, studies, training and research. Businessmen add to universities through their investment and their expertise, offering insight on 
efficiency of production, services and the needs of the market in terms of training, competency and qualifications.

Implement the Productive University concept (meaning that the university could offer value to its community). As mentioned, the university could offer training and awareness programs that serve the needs of different sectors in the community. In turn, the community could constitute a valuable financial resource through business incubators, houses of expertise and research consultancy. Through high-profile events, capital owners could be invited to attend university events and seminars and perhaps be encouraged to give back. Furthermore, increased attention should be devoted to scientific research. This could be achieved by working on topics of high interest to society or those that represent threats or challenges on various fronts. Towards this end, research centers could be established at each university with the aim of being directly relevant and beneficial to the wider community.

There is little room for self-funding in HEIs in Arab countries, most of which is derived from student fees, including registration, student activities, exams and graduation fees. Nevertheless, these remain mostly nominal amounts. Therefore, it is now imperative to work toward increasing the allocations and resources for HEIs in the region. Diversifying and introducing institutional financial revenue sources is one practical means to proceed towards improvement. For Banya (2005), increasing private institutes is a significant way to diversify a nation's HE system financially that allows for more enrollments to HE without increasing government expenditure. Moreover, HEIs in this context suffer from weak and limited external funding, whether in the form of grants or loans. This is due in part to the special nature of external funding, subject as it is to political fluctuations, calculations and other factors that are difficult to control. Therefore, external funding must be deemed a secondary, rather provisional source, applicable only under certain conditions and not a reliable, invariable primary source. Thus, establishing other education paradigms and competitive funding mechanisms to provide universities with additional financial revenue sources could be considered. Partnerships may as well be crucial for greater institutional and managerial efficiency and cost-effectiveness and ensure competitive teaching. Despite these limitations, care should be taken to promote cultural relationships with HE in their nations, not only for the opportunity of financial gains but also for the enrichment that ensues from cultural and intellectual interaction (Al-Sahlawi, 2000). Finally, it could be argued that fund-related strategies and policies must be implemented in order to increase the government's financial resources allocated to the HE in the Arab countries. Such policies should not only aim to improve the efficiency of government funding but also to allow non-governmental alternatives to flourish. Specifically, planning is a potential component of funding HE in Arab countries (Al-Beheiri, 2004).

\section{Conclusion}

The review has allowed us understanding that HE seems to be a key element in educational and political agendas in Arab countries. However, the economic and environmental complications embedded this context (Badran et al., 2019) requires the obtainability of more financial flows and resources, which are unaffordable for most countries in the region, to tackle the multiple challenges (Hillman \& Baydoun, 2019). The review highlighted major constraints and challenges facing HE financing in the region, which certainly affects the flow of adequate finance provided to HEIs. The need to acknowledge the constraints associated with limits on finance is fundamental for declining the hazardously high levels of unemployment (even of HE graduates) for a sustainable economic growth. These include brain drain, a gap between educational outcomes and the labor market, a reliance on policy learning and dependency on others, financial crisis, a shortage of governmental resources, and poor participation pf private sector and civil society. Hence, the majority of the studies reflect numerous challenges, rather than seriously seeking practical ways to overcome or at least easing their implications, especially within the changing social demands and political challenges in the region which have recently emerged, e.g. public movements against the political regimes including anti-government protests and pro-democracy uprisings. Therefore, attention should be paid to investigate this topic locally and globally within this unstable newly-shaped political environments of most countries. Specially, many of these countries have "chronic weaknesses of their public finances" (Hillman \& Baydoun, 2019, p. 27), which has placed HE under pressure.

The various constraints and challenges identified are based on insightful theoretical constructs that are highly characterized by principles and concepts, which may not allow us to practicably develop a clear understanding of how to inspire the development of HE finance that would be a concern of policymakers and speedily acts on policy making. However, the integration of such theoretical constructs (or others) and the introduction of serious attempts or thoughtful scenarios towards practical applications seem to be ignored. We suggest that a greater participation of community and people to support the governments in the responsibility for financing HE will be necessary. Moreover, diversifying funding sources and building mutual interaction and engagement between HEIs and business entities would have several advantages. It would help to address the socio-economic problems faced by HEIs, increasing financial support and investment in education more productively. Finally, quantitative and mixed method research designs, and cross-sectional and panel analysis data are recommended to assess the influence of the HE finance systems and to identify the best opportunities and ways to meet challenges confronted by the countries, given their social and political paradigms. 
This review, however, is not without its limitations. The search process is limited to the published literature related to the topic, including e-books and journal articles available published in Arabic and English through a present researchers' university library electronic system. Likewise, given the limitations of the selection criteria, the studies that have been reviewed are limited in the RQs of this study, and in the abstracts and findings synthesized based on the pre-defined keywords. Since the studies reviewed are limited to this examined specific context, the generalizability of the findings to other contexts cannot be determined. Given the apparent similarity between the Arab countries as acknowledged in this review (see Section 2.2) and the size of the sample; it is possible that there are other research pieces that would insightfully provide analyses of the topic in a comparative perspective. This review is also limited in the used qualitative methodology. We therefore call towards including quantitative - and both qualitative and quantitativeresearch to explore the topic in future research. Accordingly, other researchers may use systematic approaches for literature review such as the "Evidence for Policy and Practice Information and Co-ordinating EPPI center" that summarizes the evidence in a narrative, transparent and sustainable manner (Gough \& Elbourne, 2002).

\section{Disclosure statement}

No potential conflict of interest was reported by the authors with respect to the research, authorship and/or publication of this article.

\section{Funding}

The author(s) received no financial support for the research, authorship and/or publication of this article.

\section{ORCID}

Huda Al-Kubaisi https://orcid.org/0000-0001-7264-9632.

\section{References}

Abdeen, M. A. (2017, April 24-26). A contemporary vision to study the dropout rate in member countries of Arab bureau of education for the Gulf States [Conference paper]. International Educational Conference held by Arab Central for Educational Research of the Gulf States in cooperation with the Ministry of Education, Bahrain.

Abu Al-wafa, J., \& Abualadim, S. (2000). Contemporary trends in school management. Alexandria, Egypt: Dar AlMarefa Elgamaia.

Al-Agtash, S., \& Khadra, L. (2019). Internationalization context of Arab higher education. International Journal of Higher Education, 8(2), 68-81. https://doi.org/10.5430/ijhe.v8n2p68

Al-Beheiri, E. M. (2004). Funding university education in Egypt in light of contemporary global changes and trends: Future study [Unpublished doctoral dissertation]. Al Azhar University.

Al-Hilali, E. (2013, December 27-28). Contemporary trends in funding university education: A study [Conference paper]. $10^{\text {th }}$ National Conference "Future University in the Arab World." Education Development Center, Ain Shams University.

Al-Juma'ai, W. A. (2015). International contemporary trends in funding higher education: British model-A theoretical vision. Majallat Ālam al-Tarbiyah, 116(3865), 1-61.

Alkubaisi, H. (2018). Decentralized Management in Independent Secondary Schools in Qatar's Educational Reform Initiative (Unpublished doctoral dissertation). UCL Institute of Education, UCL, United Kingdom.

Alnoori, A. (1987). New trends in educational planning in Arab States. Doha, Qatar: Dar Althaqafa.

Al-Rubay'an, A. (2015). Funding higher education in kingdom of Saudi Arabia. Ministry of Higher Education: Kingdom of Saudi Arabia.

Al-Sahlawi, A. (2000). Trends on higher education expenditure and required dialogue. Educational Journal, 7(56), 105-151.

Alshamy, A. S. (2012). Funding mechanisms and quality assurance systems in higher education in Egypt in comparative perspective [Doctoral dissertation, University of Birmingham].

Al-Theibi, K. A. (2016). The future directions of research in educational management. Arab Gulf Message, 37(139), 15-37.

Arar, K., \& Oplatka, I. (2015). The effect of socio-cultural factors on the development of female education leaders in Arab societies: A review of extant literature and future directions for research, in: A. Bowers, A. Shoho \& B. Barntett (Eds.), International research on school leadership (pp.87-118). Charlotte, NC: New Information Age Publishing. 
Arar, K., \& Oplatka, I. (2017). The research on educational leadership and management in the Arab world since the 1990s: A systematic review. Review of Education, 5(3), 267-307. https://doi.org/10.1002/rev3.3095

Badran, A., Baydoun, E., \& Hillman, J. (2019). Introduction. In A. Badran, E. Baydoun, \& J. Hillman (Eds.), Major Challenges Facing Higher Education in the Arab world: Quality Assurance and Relevance (pp. 1-12). Cham, Switzerland: Springer International Publishing. https://doi.org/10.1007/978-3-030-03774-1_1

Badran, S., \& Badran, A. (2018). Who pays what for public \& private university education in the Arab region compared with the rest of the world: Context of Jordan. In A. Badran, E. Baydoun, \& J. Hillman (Eds.). Universities in Arab countries: An urgent need for change (pp. 225-248). Cham, Switzerland: Springer International Publishing. https://doi.org/10.1007/978-3-319-73111-7_13

Banya, K. (2005). Globalisation and higher education policy changes. In J. Zajda (Ed.), International handbook on Globalisation, Education and Policy Research (pp. 174-164). Dordrecht, The Netherlands: Springer.

Beltagi, M. (2012). Higher education in Egypt between funding constraints and development strategies. Journal of Economics and Political Sciences, 16(3), 1-30.

Beltagi, M. (2015). Funding higher education in Egypt-problems and suggested solutions. Journal of College of Economics and Politics, 16(3), 1-25.

Blanchard, O. J. (2017). Macroeconomics (7th ed.). Boston, MA: Pearson Education.

Boell, S. K., \& Cecez-Kecmanovic, D. (2015). On being 'systematic' in literature reviews. In L. P. Willcocks, C. Sauer, \& M. C. Lacity (Eds.), Formulating Research Methods for Information Systems (pp. 48-78). London, United Kingdom: Palgrave Macmillan. https://doi.org/10.1057/9781137509888_3

Booth, A., Papaioannou, D., \& Sutton, A. (2012). Systematic approaches to successful literature review. Thousand Oaks, CA: Sage.

Bowers, A. J., Shoho, A. R., \& Barnett, B. G. (2015). The multiple futures of the field of educational leadership research and practice - An introduction. In A. J. Bowers, A. R. Shoho, \& B. G. Barnett (Eds.), Challenges and Opportunities of Educational Leadership Research and Practice: The State of the Field and Its Multiple Futures (pp. 1-14). Charlotte, NC: Information Age Publishing Inc.

Bruner, J. S. (1996). The Culture of Education. Cambridge, MA: Harvard University Press.

Buckner, E. (2011). The role of higher education in the Arab state and society: Historical legacies and recent reform. Comparative and International Higher Education, 3, 21-26.

Cho, Y., \& Marshall Egan, T. (2009). Action learning research: A systematic review and conceptual framework. Human Resource Development Review, 8(4), 431-462. https://doi.org/10.1177/1534484309345656

Davies, D., Jindal-Snape, D., Collier, C., Digby, R., Hay, P., \& Howe, A. (2013). Creative learning environments in education-A systematic literature review. Thinking Skills and Creativity, 8, 80-91. https://doi.org/10.1016/j.tsc.2012.07.004

Dixon-Woods, M. (2011). Using framework-based synthesis for conducting reviews of qualitative studies. $B M C$ Med, 9(39), 1-2. https://doi.org/10.1186/1741-7015-9-39

Drori, G. S. (2000). Science education and economic development: Trends, relationships, and research agenda. Studies in Science Education, 35(1), 27-57. https://doi.org/10.1080/03057260008560154

Fehnel, R. (2004). Higher education reforms and demand responsive innovation funds: Dimensions of difference. Retrieved from: http://siteresources.worldbank.org/INTAFRREGTOPTEIA/Resources/fehnel_ino v.pdf

Ghanem, M. (2000, April 17-19). Developmental role of Arab universities and untraditional funding resources [Conference paper]. International conference accompanied to the 33th session of Arab Universities Union, Beirut.

Goastellec, G. (2005). Towards an economy of access: Changes in funding equality of opportunities [Conference paper]. RESUP Symposium, Thematic: The market for resources. Retrieved from fr/manifestations/conferenceinternationaleparis2007/Actes/GaeleFundingEquity.pdf

Gough, D. (2007). Weight of evidence: A framework for the appraisal of the quality and relevance of evidence. Research Papers in Education, 22(2), 213-228. https://doi.org/10.1080/02671520701296189

Gough, D., \& Elbourne, D. (2002). Systematic research synthesis to inform policy, practice and democratic debate. Social Policy and Society, 1(3), 225-236. https://doi.org/10.1017/S147474640200307X

Hallinger, P., \& Hammad, W. (2019). Knowledge production on educational leadership and management in Arab 
societies: A systematic review of research. Educational Management Administration and Leadership, 47(1), 20-36. https://doi.org/10.1177/1741143217717280

Hanieh, A. (2016). The world social science report 2016, inequalities in the Arab region. United Nations Educational, Scientific and Cultural Organization (UNESCO). Paris: France and the International Social Science Council (ISSC). Retrieved from: https://en.unesco.org/inclusivepolicylab/sites/default/files/analytics/document/2019/4/wssr_2016_chap_19.pdf

Harvard University. (2013). Financial report fiscal year 2013. Retrieved from: https:/hwpi.harvard.edu/files/fad/files/2013fullreport.pdf

Harvard University. (2015). Financial report fiscal year 2015. Retrieved from: https://finance.harvard.edu/files/fad/files/harvard_financialreport_fy15.pdf

Harvard University. (2017). Financial report fiscal year 2017. Retrieved from: https://finance.harvard.edu/files/fad/files/harvard_annual_report_2018_final.pdf

Hemsley-Brown J. V., \& Oplatka, I. (2006). Universities in a competitive global marketplace: a systematic review of the literature on higher education marketing, International Journal of Public Sector Management, 19(4), 316-338. https://doi.org/10.1108/09513550610669176

Hillman, J. R., \& Baydoun, E. (2019). Quality Assurance and Relevance in Academia: A Review. In A. Badran, E. Baydoun, \& J. Hillman (Eds.), Major Challenges Facing Higher Education in the Arab World: Quality Assurance and Relevance (pp. 13-68). Cham, Switzerland: Springer International Publishing. https://doi.org/10.1007/978-3-030-03774-1_2

IMF. (2011). Regional economic outlook: Middle East and Central Asia. World Economic and Financial Surveys, 39, 11 April. Washington DC, IMF. https://doi.org/10.5089/9781616350642.086

International Labour Organization [ILO] (2019). World employment and social outlook - Trends 2019: Poor working conditions are main global employment challenge. Retrieved from: https://www.ilo.org/global/about-the-ilo/newsroom/news/WCMS_670171/lang--en/index.htm

Johar, A. S., \& Al-Basil, M. (2015). The best investment in education financing. Al-Mansoura, Egypt: The Modern Library for Publishing and Distribution.

Karakhanyan, S. (2019). Quality Assurance in the Arab Region in the Era of Customization: Where Do We Stand in Terms of Relevance? In A. Badran, E. Baydoun, \& J. Hillman (Eds.), Major Challenges Facing Higher Education in the Arab World: Quality Assurance and Relevance (pp. 211-223). Cham, Switzerland: Springer International Publishing. https://doi.org/10.1007/978-3-030-03774-1_10

Kudrle, R. (2014). The OECD and the international tax regime: Persistence pays off. Journal of Comparative Policy Analysis: Research and Practice, 16, 201-215. https://doi.org/10.1080/13876988.2013.834642

MacLeans, A. G. (2005). Globalisation, Education Reforms and Policy Change in Africa: The Case of Nigeria. In J. Zajda (Ed.), International handbook on Globalisation, education and policy research (pp. 501-516). Dordrecht, The Netherlands: Springer.

Mallett, R., Hagen-Zanker, J., Slater, R., \& Duvendack, M. (2012). The benefits and challenges of using systematic reviews in international development research. Journal of Development Effectiveness, 4(3), 445-455. https://doi.org/10.1080/19439342.2012.711342

Merhan R. (2018). The World Bank's support to higher education reform in Egypt: Educator's perspective on its impact for quality and equality [Unpublished master's thesis]. The American University in Cairo, Egypt.

Michie, S., \& Williams, S. (2003). Reducing work related psychological ill health and sickness absence: a systematic literature review. Occupational and Environmental Medicine, 60(1), 3-9. https://doi.org/10.1136/oem.60.1.3

Muhammad, T. A. (2006). A proposal to fund university education in Arab countries in light of contemporary trends [Unpublished doctoral dissertation]. Mohammed Khader University.

Oakley, A. (2003). Research evidence, knowledge management and educational practice: early lessons from a systematic approach. London Review of Education, 1(1), 21-33. https://doi.org/10.1080/14748460306693

Office of Institutional Research and Assessment. (2019). American university of Beirut facts and figures 2019. Retrieved from: https://www.aub.edu.lb/AboutUs/Documents/Facts-Figures-2019.pdf

Organization for Economic Cooperation and Development (OECD) \& World Bank. (2010b). Reviews of national policies for education: Higher education in Egypt. OECD and IBRD/World Bank. 
Organization for Economic Cooperation and Development (OECD). (2010a). OECD science, technology and industry outlook 2010. Paris, France: OECD.

Ozden, C. M. (2006). Brain drain in Middle East \& North Africa - the patterns under the surface. [Conference paper]. United Nations Expert Group Meeting on International Migration and Development in the Arab Region Population Division Department of Economic and Social Affairs United Nations Secretariat, Beirut.

Portnoi, L. (2005). Employment equity and higher education: Policy borrowing and the politics of language. In J. Zajda (Ed.), International handbook on Globalisation, education and policy research (pp. 351-365). Dordrecht, The Netherlands: Springer. https://doi.org/10.1007/1-4020-2960-8_22

Psacharopouls, G., \& Sanyal, B. C. (1981). Higher education and employment: The IIEP experience in five less developed countries. UNESCO/IIEP.

Saa'q, A. (1986). The American experience in funding higher education and some of its usefulness in developing the current situation of funding higher education in the Arab world. Journal of Arab Universities Federation, 21, 62-6.

Sabry, M. (2009). Funding policy and higher education in Arab Countries. Journal of Comparative \& International Higher Education, 1(Fall), 11-12.

Sanyal, B. C. (1998). Diversification of sources and the role of privatization in financing higher education in the Arab Region, UNESCO regional office for Education in The Arab States, Arab Regional Conference on Higher Education, Beirut, 2-5 March, p. 3.

Sanyal, B. C., \& Martin, M. (2006a). Financing higher education: international perspectives. World, 8(2), 23-2.

Sanyal, B. C., \& Martin, M. (2006b). Financing higher education: International perspectives. In Global University Network for Innovation (Ed.), Higher education in the world: The financing of universities. Basingstoke and New York: Palgrave Macmillan.

Schultz, T. W. (1961). Investment in human capital. The American Economic Review, 51(1), 1-17.

Seabrooke, L. (2012). Pragmatic numbers: the IMF, financial reform and policy learning in least likely environments. Journal of International Relations and Development, 15, 86-505. https://doi.org/10.1057/jird.2012.2

Sellami, A. L., Sawalhi, R., Romanowski, M. H., \& Amatullah, T. (2019). Definitions of educational leadership-Arab educators' perspectives. International Journal of Leadership in Education. https://doi.org/10.1080/13603124.2019.1690701

Shaa't, M. (1997). The reality of funding university education and its future from the point of view of those in charge of the Palestinian university, the education council, and the state bodies. [Unpublished master's thesis]. An-Najah National University, Education Council, and Sate Bodies, Nablus, Palestine.

Shaheen, M. A. (2016). Funding higher education in Palestine between reality and hopes. Retrieved from: http://www.noqta.info/page-101825-ar.html

Smith, W. C. (Ed.). (2016). The global testing culture: Shaping education policy, perceptions, and practice. Oxford, United Kingdom: Symposium Books. https://doi.org/10.15730/books.94

Tarawneh, E. (2011). Assessing and understanding quality in Arab reform. In T. Townsend \& J. MacBeath (Eds.), International handbook of leadership for 152 learning, Springer international handbook of education (Vol. 25) (pp. 1107-1123). Dordrecht, Netherlands: Springer. https://doi.org/10.1007/978-94-007-1350-5_60

Taylor, F. (2003). Content analysis and gender stereotypes in children's books. Teaching Sociology, 31(3), 300-311. https://doi.org/10.2307/3211327

Thomas, J., \& Harden, A. (2008). Methods for the thematic synthesis of qualitative research in systematic reviews. BMC Medical Research Methodology, 8(1), 45. https://doi.org/10.1186/1471-2288-8-45

Thorpe, R., Holt, R., Pittaway, L., \& Macpherson, A. (2006). Knowledge within small and medium sized firms: A systematic review of the evidence. International Journal of Management Reviews, 7(4), 257-281. https://doi.org/10.1111/j.1468-2370.2005.00116.x

Tilak, J. (1997). Lessons from cost recovery in education. In C. Coclough, (Ed.), Marketising education and health in developing countries (pp. 63-89). Oxford, United Kingdom: Oxford University Press.

Tilak, J. B. G. (2006). Global trends in funding higher education. International Higher Education, 42, 5-6.

Tilak, J. B. G. (2005). Global trends in the funding of higher education, IAU Horizons, World Higher Education News, 11(1), 1-3. 
UNESCO. (2013). UNESCO Handbook on education policy analysis and programming, Volume 1, Education policy analysis. Bangkok: UNESCO Bangkok Asia and Pacific Regional Bureau for Education. Retrieved from http://unesdoc.unesco.org/images/0022/002211/221189E.pdf

UNESCO. (2018). UNESCO study report on financing higher education in Arab states. UNESCO Regional Bureau for Education in the Arab States: Beirut. http://www.unesco.org/new/fileadmin/MULTIMEDIA/FIELD/Beirut/video/Report.pdf

UNICEF Regional Office for CEECIS. (2014). Financing collective education booklet. Retrieved from: https://hisweekinpalestine.com/wp-content/uploads/2019/03/Mar-2019-251.pdf

United Nations Development Program (UNDP) \& Regional Bureau for Arab States (RBAS). (2016). Arab Human Development Report 2016: Youth and the Prospects for Human Development in Changing Reality. New York: United Nations Development Programme, Regional Bureau for Arab State). Retrieved from: http://www.arab-hdr.org/reports/2016/english/AHDR2016En.pdf

Weed, D. L. (2005). Weight of evidence: a review of concept and methods. Risk Analysis: An International Journal, 25(6), 1545-1557. https://doi.org/10.1111/j.1539-6924.2005.00699.x

Weitzman, L. J., Eifler, D., Hokada, E., \& Ross, C. (1972). Sex role socialization in picture book for pre-school children. American Journal of Sociology, 77(6), 1125-1150. https://doi.org/10.1086/225261

World Bank (2019a). Expectations and aspirations: A new framework for education in the East and North Africa-Overview. Washington DC: International Bank for Reconstruction and Development-The World Bank. Retrieved from:

http://documents.worldbank.org/curated/en/527931542039352771/pdf/131974-WP-v1-PUBLIC-nov13-6am-3325 $5 \mathrm{cmp}$-eproof.pdf

World Bank (2019b). Unemployment, total: \% of total labor force-national estimate. Retrieved from https://data.worldbank.org/indicator/SL.UEM.TOTL.NE.ZS?locations=1A

World Bank (2019c). Unemployment, total: \% of total labor force- modeled ILO estimate. Retrieved from https://data.worldbank.org/indicator/SL.UEM.TOTL.ZS

World Bank. (2000). Higher education in developing countries: perils and promise. Washington, DC: World Bank.

\section{Copyrights}

Copyright for this article is retained by the author(s), with first publication rights granted to the journal.

This is an open-access article distributed under the terms and conditions of the Creative Commons Attribution license which permits unrestricted use, distribution, and reproduction in any medium, provided the original work is properly cited. 